\title{
Kurmacanın İnşası
}

\section{The Construction of Fiction}

Emre Yalçın, Sahne Sanatları Bölümü, Kafkas Üniversitesi

\author{
Oğuz Arıcı. (2020). Kurmacanın İnşası: Oyun Yazarlığına Giriş [The construction of \\ fiction: Introduction to playwriting] İstanbul: Habitus Yayıcllık, 344 s.
}

\begin{abstract}
Küresel salgının yaşattığı zor zamanları deneyimlemeye devam ederken yazarlık öğrencileri, oyun yazarları ve yazarlık alanında çalışan akademisyenler için sevindirici bir haber Habitus Yayıncllık'tan geldi. Oğuz Arıcı'nın 'yazarlık' alanına önemli katkılar koyacak çalışması Kurmacanın İnşası, geçtiğimiz günlerde sessiz sedasız tiyatro literatürümüze katıldı. Arıcı'nın dramatik yazarlık derslerinin ve tiyatro kuramı, felsefe, tarih, edebiyat, dilbilim gibi birçok disiplin arasındaki okumalarının bir uzantısı olarak șekillenen kitap, sadece oyun yazarları için değil, oyuncular, yönetmenler, dramaturglar, hatta sinema, roman, öykü ve şiir sanatlarıyla ilgilenenler için de kafa açıcı bir kaynak niteliği taşıyor. Yazar kitapta dramatik edebiyatın konvansiyonlarını, yazma stratejilerini, kurucu düşünceler ve açıklayıcı kavramlar üzerinden inceliyor. Bu doğrultuda 'olay örgüsü', 'iç aksiyon-dış aksiyon', 'pathos (duygusal etki)', 'metin-alt metin', 'çatışma', 'karakter', 'diyalog', 'tempo-ritim' gibi kurmacayla uğraşan bütün sanatlar için hayati olan birçok nosyonu, zengin referanslarla, ayrıntılı bir şekilde ele alıyor.
\end{abstract}

'Kurmacanın İnşası' üç ana başlıktan oluşuyor: 'Kurmaca Nedir?', 'Dramanın Öğeleri' ve 'Yazma Sorunu Üzerine Düşünceler'. Kitabın sonunda bir de son söz bölümü var: 'Yazmak Yeniden Yazmaktır'. Birinci bölümün temel hareket noktasını Aristoteles ve onun 'Poietika' isimli eseri oluşturuyor. Arıcı, ilk olarak Poietika'nın Yunancadan Latinceye çevrilirken geçirdiği anlam kaybı üzerinde duruyor. Kitabın orijinal ismi 'peri poietikes'. Ancak Aristoteles'in kitapta, nazım türlerinden epos ve tragedyaya odaklanmasının da etkisiyle birçok dilde 'șiir sanatı üzerine' ya da 'șiir sanatı hakkında' olarak çevriliyor. Oysa 'poietike' sözcüğünün kökeni, Yunancada yapmak, etmek, davranmak, üretmek gibi anlamlara gelen 'poiein' fiilinden gelmekte. Aynı kökenle bağlantılı olarak 'poiema', yapılmış şey, eser, ürün; 'poietes' ise eser ortaya koyan kişi anlamına geliyor. Buralardan hareketle Arııı, Poietika'nın şiir sanatı üzerine değil, genel anlamıyla sanat üzerine bir kitap olduğu, hatta 'poietika' sözcügünün Türkçedeki 'sanat' sözcügünün tam karşılığı olduğunu ileri sürüyor. Arıcı'ya göre, tıpkı 'poiein' fiili ve türevleri arasındaki bağlantılar gibi, Arapçadan dilimize geçen 'sanat' sözcügü,, 'san'a' (yapmak, etmek) fiilinden gelmekte ve bu fiilden de 'suni' (yapay), 'sanat' (yapılan iş, meslek), 'sanayi' (sanat'ın çoğul hali) gibi sözcükler türemekte. Yazar, benzer yapıların Almanca'da Kunst, Kunstlich ve İngilizce'deki Art, Artificial sözcükleri arasında da görülebileceğini ekliyor (Arıcl, 2020, s. 14-15).

Aristoteles, Poietika'da her ne kadar sanata, insanın poietik etkinliğinin bir bölümünde (epos, tragedya, komedya, dytrambos gibi) yoğunlaşıp resim ve heykel gibi diğer mimetik sanatlara fazla değinmese de sanat üretimine, onun doğayla olan ilişkisine, sanatçıya ve mimesise dair açıklamalarıyla aslında diğer sanatları da ilgilendiren çok şey söylüyor. Bu bakımdan Arıcı'ya göre, sanatların bütününe yönelik bir kitap olarak Poietika'nın en önemli tarafını, ilk kez 'kurmaca' fikri üzerinde durması ve 'mimesis' kavramına, şeylerin kopyalanması anlamının dışında bir anlam yüklemesi oluşturuyor. Bu doğrultuda Aristoteles'in mimesis ile tarif ettiği ve hocası Platon'a karşı çıktığı esas, mimesis'in bir kopyalama ya da benzerini yapma işi değil, temsil etme, işaret etme, gösterme ve yeniden inşa etme süreci olduğudur. İnsanın, doğanın yöntemine öykünerek ikinci bir doğa yaratmasıdır (Arıcı, 2020, s. 31). İnsanın doğanın yöntemine öykünmesi ne demektir? Arıı bu soruyu, Aristoteles'in terminolojisinde önemli yer tutan üç kavramın birbiriyle ilişkisi ve birbirinden nasıl ayrıldıkları üzerinden açıklıyor: phusis (doğa), tekhne ve poiesis.

- $\quad$ Sorumlu Yazar: Emre Yalçın, Sahne Sanatları, Kafkas Üniversitesi.

- $\quad$ Adres: Kafkas Üniversitesi, Merkez Yerleşkesi, Güzel Sanatlar Fakültesi Sahne Sanatları Bölümü, Kars.

- e-posta: yalcemre@gmail.com

- ORCID: 0000-0003-3569-5730

- Cevrimiçi yayın tarihi: 09.04.2021

- doi: $10.17484 /$ yedi.869466 
Arıcı'ya göre, Aristoteles için phusis (doğa), sadece etrafımızı kuşatan şeylerden ibaret değildir. Aynı zamanda şeylerin içinde yer alan, şeylerin hareketinin ve hareketsizliğinin ilk nedeni, ilk ilkesidir ('arkhesi'dir). Kendi üretiminin 'arkhe'sini ve amacını ('telos'unu) kendi içinde taşıyan, Heidegger'in dediği șekilde șeyin kendi içerisinden patlayıp çiçeklendiği bir mevcudiyete çıkmadır. Mevcut olmayandan mevcut olana çıkma, Yunanlılar için 'poiesis'tir. Dolayısıyla phusis, yani doğa da bir 'poiesis'tir. Fakat sanat gibi olagelmesi için kendi dışında bir 'poietes'e, yapıcıya, sanatçıya ihtiyaç duymamaktadır. Poietes olarak insan, tekhne, sanat ve el becerisiyle ve bir şeyin öne çıkmasına katkıda bulunan madde ve görünüm gibi unsurlarla birlikte, doğanın yöntemine öykünerek 'poiema'yı (eserini) üretir. Sanatçının üretimi böylelikle Platon'un düşündüğü gibi şeylerin münferit varlıklarının basit bir şekilde kopyalanması ile ilgili bir süreç değil, şeylerin genel özleriyle teknik, beceri ve sanat yoluyla ilişki kuran, doğanın yöntemine öykünerek onların özünü taklit ya da temsil eden bir yaratma işidir (Arıcı, 2020, s. 23-24).

Arıcı, bu şekilde, mimetik sanatların ve dramatik edebiyatın temelleri, kurucu düşünceleri ve temel kavramları üzerinden sanat üretimine, sanatçıya ve onların dünyayla olan ilișkisine dair ontolojik bir çerçeve oluşturduktan sonra esas konusu 'kurmacaya' odaklanıyor. Bu doğrultuda, Aristoteles ve Poietika etrafında çizdiği düşünsel dairelere devam ediyor. Poietika'da Aristoteles, tragedyanın en önemli unsurunu 'olay örgüsü' olarak belirlemiştir. Aristoteles'e göre olay örgüsü doğru bir şekilde kurulmamış bir metnin başarılı bir tragedya olması imkânsızdır. Dahası, onun nazarında karakteri bulunmayan bir tragedya mümkün olabilir, ama olay örgüsü olmayan bir tragedyadan bahsedilemez. Buna bakımdan, insan eylemleri belirli bir düzen içerisinde kompoze edilmelidir. Böylelikle 'poiesis'in öznesi olarak ozanın kompozisyon iși, kurmacanın inşasıdır (Arıcı, 2020, s. 32). Buradaki 'kurmaca' terimi, olmayan bir şeyi tasarlama, hayali olgu ve olayların kurgulanması gibi anlamları barındıran, olayların olasılık ve zorunluluk yasalarına göre düzenlenmesi anlamına gelmekte. Böylelikle edebiyatın yaptığı mimesis, 'olan șeylerin' yeniden kurgulanarak anlatımından ziyade 'olası olanın' ve tümelin belirli bir tertip/kompozisyon içinde 'inşa' edilmesidir (Arıcl, 2020, s. 33).

Yazar, kitabın ikinci bölümünü ve en geniş parçasını oluşturan 'Drama'nın Öğeleri' bölümünde, kurmacaya dönük gerçekleşmesi gereken bu inşa sürecinde yer alan drama tekniklerine, dramatik öğelere ve anahtar kavramlara dair mikroskobik bir bakış geliştiriyor. Bu bakışı, yine Aristoteles'in Poietika'da belirlediği temel ilkeler üzerinden gerçekleştiriyor. Bölümün alt başlıkları, Aristoteles'in tragedyanın altı bileşeni olarak gördüğü Mythos (olay örgüsü), Ethos (karakter), Diaonia (düşünce), Lexis (dil kullanımı ve diyalog), Opsis (mekân kullanımı ve dekorasyon) ve Melos (ritim, tempo, melodi) olarak şekilleniyor. Yazar, 'Mythos: Olay Örgüsü’ başlı̆̆ının altında, olay örgüsünün ne anlama geldiği, öyküden nasıl ayrıldığı üzerine bir tartışma yürüttükten sonra düşüncelerini 'Oidipus Tyrannos' ve 'Hamlet' metinlerinin olay örgüleri üzerinden örnekliyor. Sonrasında, dış aksiyon-iç aksiyon, metin-altmetin, oyunlardaki dönüşümler (peripeteia, epifani ya da anagnorisis), pathos-katharsis, merak, olasılık-zorunluluk, çatışma-engel gibi alt başlıklarda dramatik konvansiyonları ve yazma stratejilerini, literatürdeki diğer kuramsal ve sanatsal yaklaşımları da göz önünde bulundurarak analiz ediyor. 'Ethos: Karakter' başlığında ise, karakterizasyon tekniklerine ve 'arzu', 'engel', 'itki', 'gerekçe', 'antagonist' gibi karakteri belirleyen temel unsurlara yoğunlaşıyor. Sonrasında karakterdeki değişimler ve karakterin boyutlandırılması gibi konulara eğiliyor.

Dionia (Düşünce) bölümüne ise yazar, oyun metnini oluşturan temel unsurlarından biri olan, 'dionia'nın, Poietika'da iki anlamda kullanıldığı tespitiyle başlıyor. Birinci anlam, kanıtlama, çürütme ve duygu uyandırma gibi konuşmanın öğelerinde kendini gösteren ve bu bakımdan retorik ve politik sanatların konusu olan şey, ikincisi ise söz dışında, eylemler yoluyla görünür olan şey (Arıcı, 2020, s. 179). Ardından Arıcı, günümüzde dionia yerine geçen kavramlar olarak tema, anlam, ileti, mesaj ve önerme gibi terimleri Grebanier, Lajos Egri, William Archer, Walter Kerr ve John Castello gibi kuramclların da düşünceleriyle birlikte tartışmaya açıyor. Bu tartışmanın sonunda, yazarlıkla uğraşan okuyucuya temel önerisi çalışmalarında fazlasıyla soru üretmeleri ve sorulardan yola çıkarak kompozisyonlarını geliştirmeleri yönünde. Yazara göre, eğer bir oyun yazarı etik metafizik, toplumsal ya da politik bir konuda seyircinin sorular sormasını sağlıyorsa, oyun en azından 'dionia' bakımından amacına ulaşmıș demektir (Arıcl, 2020, s. 183).

Arıcı, Lexis bölümünde, oyun yazımında en büyük problem olarak karşımıza çıkan diyalog yazımı problemine eğiliyor. Öğrencileri üzerindeki gözlemlerine de dayanarak, yazar adaylarının oldukça yaratıcı olay örgüleri yaratsalar da aynı başarıyı diyalog yazımında çoğu zaman gösteremediklerini belirtiyor. Yazara göre, bu sorunun birkaç temel sebebi var. Birincisi, kültürel olarak diyalojik düşünmekten ziyade monolojik düşünme eğilimimiz. Oysa, yazarların karakterleri birbirinden farklılaştırması ya da oyunun düşüncesini derinlemesine tartıştırabilmesi için, öncelikle kendilerinin tartışmaya, eleştiriye, müzakereye ve farklı düşüncelere açık olması gerekiyor. İkincisi, Arıcı'ya göre 'diyalog' edebiyatın en zor ve en fazla tekniğe gereksinim duyan öğesi. Bu bağlamda ilk vurgulanması gereken şey, herhangi bir kurmaca metnindeki diyaloğun günlük dildeki gerçek konuşmadan farklı olduğu. Oyun yazarlığı tekniği üzerine yazılmış birçok kitapta yazar adaylarına hayatı, insanları ve olayları gözlemlemesi, hatta diyalogla ilişkili 
olarak gerçek bir konușmayı kayda geçirmeleri önerilse de, yazara göre bu tür bir yaklașım, sanatı hayatın bir kopyası olarak gören paradigmanın devamından başka bir şey değil. Burada gerçekle, gerçekçilik bir kez daha birbirine karıştırılıyor, oysa ki:

Shakespeare'in yaşadığı sokaklarda kimse iambic pentameter ölçüsüyle konuşmuyordu ya da Atina meydanında kral, haberci ve rahipler dışında kalan halk dertlerini koro halinde, tek bir ağızdan şarkı söyleyerek anlatmıyorlardı... Gerçeğin kendisiyle onun temsili/taklidi ayrı șeylerdir. Son kertede pipo resmiyle gerçek bir pipo arasında fark vardır. (Arıcl, 2020, s. 200)

Arıcı'nın dramatik metinlerde mekânın kullanımına (opsis) dair düşünceleri, özellikle de 'mekân birliği' meselesine dair yaklaşımı oldukça ilgi çekici. Birçok tiyatro tarihçisinin ve kuramcısının ortaklaştığı bir başlık olarak, 'mekân birliği'ni ilk olarak Aristoteles'in savunduğu düşüncesi Arıcı'ya göre gerçekleri yansıtmıyor. Yazara göre, Aristoteles'in mekânın tekilliği ya da değişmezliği üzerine herhangi bir yerde geçen bir ifadesi yok. Kaldı ki, Aiskhylos'un 'Persler', Oresteia üçlemesinin ikinci oyunu olan 'Sunu Taşıyanlar' ve aynı üçlemenin üçüncü oyunu olan 'Hayırlı Tanrıçalar' oyunlarında mekân değişimleriyle karşılaşıyoruz. Ayrıca Sophokles'in 'Aias' oyununda da, mekânın belirgin bir şekilde değişimine şahit oluyoruz. Arıcı, mekân birliğinin Aristoteles'e ve Antik Yunan tragedyalarına dayandırılmasını, Rönesans sonrası üç birlik kuralı düşüncesini savunanların geliştirdiğini düşünüyor (Arıcı, 2020, s. 305).

'Dramanın Öğeleri' bölümünün son bașlığına yazar, Aristoteles'in Poetika'da dramanın altı öğesinden biri olarak gördüğü melos'u sadece bir şarkı ve ezgi yapımı olarak tanımlanmadığının, terimin aynı zamanda ritim ve tempoyu da kapsadığının altını çizerek başlıyor. Her ne kadar günümüzde artık ölçülü dizelerle oyun yazılmasa da, oyunlarda 'ritim', 'tempo' ve 'mod', duyguları ifade etmek, düzenlemek ve harmonik bir biçimde bir araya getirmek için hayatiliğini sürdürüyor. Yazar bu bölümün ilerleyen kısımlarına, ritim ve tempo terimlerinin ne anlama geldiğini ve birbirlerinden nasıl farklılaştıklarını detaylı bir şekilde ele alarak devam ediyor.

Buraya kadar kitap hakkında söylenenlerden, kitabın kuramsal yoğunluğu ve derinliğiyle anlaşılması güç bir yapıya sahip olduğu fikrine kolayca kapılınabilir. Ancak, durum pek öyle değil. 'Kurmacanın İnşası', yakaladığı kuramsal derinliği ve buradan yürüttüğü tartışmaları, somut örnekler ve yalın bir anlatımla okuyucunun zihninde berraklaştırıyor. Bu bakımdan kitap boyunca, Oğuz Arıcı'nın konuya olan hakimiyetini, karmaşık ve kuramsal açıdan zor meseleleri en basit ve anlaşlır şekilde okuyucuya aktarmasıyla görüyoruz. Bunun yanı sıra, kitabın kuramsal zenginliğinin yanında, içerdiği bolca örnek, şema, tablo, okuma çalışmaları ve yazma alıştırmalarıyla yazarlık eğitimi için bir ders kitabı niteliği taşıdığını belirtmeliyiz. Kitapta, ele alınan dramatik öğelere, yazma stratejilerine ve dramatik konvansiyonlara dair 46 tane yazma alıştırması ve 4 tane de okuma çalışması bulunuyor. Bu alıştırmaların ve okuma başlıklarının her biri, kuramsal girdileri pratik deneyimlere dönüştürecek, edinilen bilgiyi yazma ve okuma süreçleriyle pekiștirecek birer işleve sahip. Kitabın son iki bölümünde Arıcl, yazar adaylarının yazma süreçlerinde karşılaşacakları teknik problemlere dair çözümlemeler yapıp somut önerilerde bulunuyor. "Öncelikle yazma sürecinin tanrı vergisi bir yetenek işi ya da iyi yazarların esin perileri olduğu efsanelerini unutmamız gerekiyor" diyor (Arıcı, 2020, s. 323). Birkaç sayfa sonra da final cümlelerinde şunları ekliyor:

Zaman zaman kâğıt rulosunu daktilosuna takıp hiç durmadan yazarak romanını bitiren yazarlardan söz edilir. Ya da esin yoluyla şiirlerini yazdığını söyleyen şairler vardır. Esin gelmiş, neredeyse bileğinden tutup ona şiirini yazdırmış gibidir. Bu tür hikâyeler edebiyat dünyasının hoş mitleridir. Başka bir deyişle, kurmaca dünyasının 'kurmacalarıdır'. Gerçekte eserler bu şekilde, bir anda, kendiliğinden ortaya çıkmazlar. (Öyle olsa bile bu bilginin hiç kimseye bir faydası yoktur.) Herhangi bir dramatik edebiyat metninin esinle, bilinç akışıyla ya da tekniğe dayanmayan bir şekilde ortaya çıkması mümkün değildir. Kurmaca işi bir imal ve inşa etme sürecidir. Yani 'poiesis'tir. (Arıcı, 2020, s. 326)

Oğuz Arıcı, ülkemizdeki en önemli Antik Yunan Tiyatrosu araştırmacılarından birisi. Daha önce kaleme aldığı 'Antik Yunan Tragedyasında Ölçülülük (Sophrosyne) ve Uyum (Harmonia)' isimli yüksek lisans tezi ve bu çalışmanın bir devamı niteliği taşıyan 'Muğlaklık ve Tragedya' başlıklı doktora tezi dilimizde tragedyalar üzerine yazılmış değerli kaynaklar arasındaki yerlerini koruyor. Ayrıca yazarın, öğretim üyesi olarak çalıştığı İstanbul Üniversitesi Tiyatro Eleștirmenliği ve Dramaturji Bölümü bünyesinde hazırlanan 'Maske Kitabı'nda (2014) ve bölüm dergisinde çeşitli editörlükleri bulunuyor. Son olarak, Arıcı'nın tiyatro ile bağlantısının sadece onun akademik kimliğiyle sınırlı olmadı̆̆ını belirtmek gerekir. Arıcı, çeşitli tiyatro topluluklarında dramaturg, yazar ve yönetmen olarak birçok çalışmaya imza atmış bir isim. Bu bakımdan 'Kurmacanın İnşası' sadece bir akademisyenin değil, aynı zamanda deneyimli ve üretken bir sanatçının üst üste dizdiği tuğlalardan oluşuyor. 